PRILOG OPTIMALNOM PROJEKTOVANJU AKTIVNOG SISTEMA ZA OSLANJANJE VOZILA

UDC: 629.012

Rezime:

U ovom radu prikazan je sistem za aktivno oslanjanje vozila, uz korišćenje ravanskog modela vozila, bez filtera u povratnim spegama sistema za regulaciju. Za optimizaciju parametara PI kontrolera korišćena je metoda stohastičke parametarske optimizacije. Cilj optimizacije bio je istovremeno minimiziranje vibracijskih ubrzanja oslonjene mase i standardnog odstupanja sila u kontaktima točkova $i$ tla, što poboljšava udobnost $i$ ponašanje vozila na putu.

Ključne reči: vozilo, aktivni sistem oslanjanja, PI kontroler, optimizacija.

\title{
A CONTRIBUTION TO OPTIMAL DESIGN OF VEHICLE ACTIVE SUSPENSION SYSTEM
}

Summary:

In this paper, an active suspension system is developed by use of a vehicle plane model without feedback filters in control system. A method of stochastic parameters optimization has been utilized in order to optimize PI controller parameters. The basic optimization goal was a simultaneous minimization of sprung mass acceleration and standard deviation of forces in tire-to-ground contact area, so as to improve vehicle comfort and handling performances.

Key words: vehicle, active suspension system, PI controller, optimization.

\section{Uvod}

Dinamičko ponašanje motornih vozila praćeno je pojavom prostornih kretanja, promenom karakteristika sa vremenom eksploatacije, velikim brojem poremećaja i sl. Pomenute dinamičke pojave, a posebno vibracije, dovode do zamora korisnika, izazivaju loše reakcije vozača, skraćuju vek vozila i njegovih sistema i sl.

Osnovni zadatak sistema za oslanjanje jeste da smanji negativne efekte, poboljša ponašanje vozila na putu i omogući njegovu eksploataciju u definisanim eksploatacionim uslovima.
Klasični sistemi oslanjanja ne mogu da zadovolje te zahteve $u$ širem dijapazonu eksploatacionih uslova, pa se pojavila potreba za uvođenjem novih sistema za oslanjanje, sa regulisanim karakteristikama (poluaktivni i aktivni sistemi). Njihove podele i klasifikacije poznate su iz literature [35].

Klasični pasivni sistemi za oslanjanje mogu ponuditi kompromis između oprečnih zahteva za oscilatornom udobnošću i ponašanja vozila na putu $[15,19$, $21,36,40]$, jer su im parametri krutosti i prigušenja fiksni. Imajući u vidu težnju za manjom potrošnjom goriva, a što se posti- 
že i manjom masom vozila, očigledno je da se aspekt opterećeno/neopterećeno stanje manifestuje kroz degradaciju parametara oscilatorne udobnosti i ponašanja vozila na putu. Samo sistemi oslanjanja sa regulisanim karakteristikama mogu na zadovoljavajući način da kompenzuju poremećaje. Prvi takav sistem korišćen je kod vasionskih letelica (Sputnjik, između 1950. i 1960. godine, [37]), dok kod motornih vozila njihova primena počinje sedamdesetih godina XX veka, i to najpre u poluaktivnom izvođenju.

U praksi postoje dve vrste sistema za oslanjanje sa regulisanim karakteristikama:

- poluaktivni, kod kojih se vrši regulacija krutosti ili prigušenja. Oni imaju povoljne karakteristike, a cena im je prihvatljiva i za vozila niže kategorije,

- aktivni, koji imaju generator sile koji može biti kombinovan i sa klasičnim elastoprigušnim elementima. Cena im je vrlo visoka, pa primenu nalaze kod vozila veoma visoke klase ili kod specijalnih vozila.

Ovi sistemi detaljnije su opisani $u$ [5-8, 11-32, 34-43].

Imajući u vidu različita konstruktivna izvođenja pomenutih sistema, $u$ ovom radu biće reči o sistemu koji se nalazi u fazi razvoja, a kod koga je ulje u hidrauličkoj instalaciji zamenjeno silikonom $[5,25,26]$ koji poseduje svojstvo elastoprigušnog elementa. Preciznije rečeno, ideja iz $[5,25,26]$ značajnije je istražena, posebno sa aspekta korišćenja integrisanog PI kontrolera i aktuatora, njegovog optimalnog projektovanja i potrebe za korišćenjem filtera $\mathrm{u}$ oblasti rezonanci oslonjenih i neoslonjenih masa. Izvršena istraživanja ilustrovana su na ravanskom modelu vozila.

Pojedine konstrukcije sistema aktivnog oslanjanja, pored generatora sile, imaju i komponente klasičnih sistema oslanjanja [5], ali će u ovom radu biti posmatran sistem koji poseduje samo generator sile, zahvaljujući osobini silikona da istovremeno ostvaruju elastično i prigušno dejstvo.

\section{Model vozila}

Razmatran je ravanski model vozila definisan na slici 1. Diferencijalne jednačine oscilatornih kretanja prikazanog modela formirane su uz primenu programskog paketa NEWEUL. Priprema ulaznih podataka izvršena je u skladu sa zahtevima računarskog programa, a za definisanje kretanja sistema sa pet stepeni slobode korišćeno je 15 koordinatnih sistema, u odnosu na koje su definisani inercijalni parametri, sile i sl. Postupak pripreme ulaznih podataka detaljno je opisan u [33].

Treba napomenuti da je vertikalna generalisana koordinata oslonjene mase definisana od željenog statičkog položaja, a generalisane koordinate masa točkova od njihovog ravnotežnog položaja, što se manifestuje tako da oslonjena masa figuriše u diferencijalnim jednačinama kretanja, a mase točkova ne figurišu u pomenutim jednačinama.

Koristeći programski paket NEWEUL i sliku 1, formulišu se nelinearne diferencijalne jednačine kretanja modela vozila: 
$m \ddot{y}=-F_{p} \sin \theta-F_{z} \sin \theta-G \sin \theta$

$m \ddot{z}=-F_{p} \cos \theta-F_{z} \cos \theta-G \cos \theta$

$I_{x} \ddot{\theta}=-F_{p} a \cos \theta+F_{z} b \cos \theta$

$m_{p} \ddot{z}_{1}=-F_{p_{1}}+F_{p} \cos \theta$

$m_{z} \ddot{z}_{2}=-F_{p_{2}}+F_{z} \cos \theta$

gde je:

$G, m, m_{p} i m_{z}-$ gravitaciona sila i mase sistema, respektivno,

$I_{x}$ - moment inercije oslonjene mase za osu $\mathrm{x}$,

$F_{p} i F_{z}$ - sile u hidrauličkim cilindrima,

$F_{p 1}$ i $F_{p 2}$ - sile u pneumaticima (usvojene

u obliku polinoma trećeg stepena [7-9, 11-15]),

$F_{d 1}$ i $F_{d 2}$ - dinamičke reakcije tla,

$\ddot{z}_{1}, \ddot{z}_{2}, \ddot{z}, \ddot{\theta}-$ ubrzanja odgovarajućih masa posmatranog sistema.

Pored navedenih, na slici 1 korišćene su i oznake $z_{01}$ i $z_{02}$ za funkcije pobude od mikroneravnina puta, a značenje ostalih oznaka na slici 1 isto je kao i u [40].

$\mathrm{Na}$ slici 2 prikazana je šema upravljanja aktivnim sistemom oslanjanja za posmatrani model vozila. U konkretnom slučaju usvojen je koncept regulacije aktivnim sistemom upravljanja, čija je osnova objašnjena u [5], a ostvaruje se preko dve grupe povratnih sprega (spoljašnja - udobnost i unutrašnja - sile).

Očigledno je da je ovaj koncept aktivnog oslanjanja zasnovan na registrovanju vertikalnih ubrzanja poskakivanja i ubrzanja galopiranja oslonjene mase, kao i hodova klipova cilindara i njihovih odgovarajućih brzina.

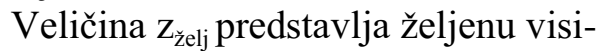
nu vozila u statičkom položaju, a $\Theta_{\check{z}}$ je željena veličina galopiranja oslonjene mase, $\mathrm{e}_{1}, \mathrm{e}_{2}, \mathrm{f}_{\mathrm{zr}}, \mathrm{f}_{\Theta_{\mathrm{r}}}, \mathrm{f}_{\mathrm{p}^{*}}, \mathrm{f}_{\mathrm{z}^{*}}, \mathrm{e}_{\mathrm{fp}}$ i $\mathrm{e}_{\mathrm{fz}}$ predstavljaju ostvarene greške u odnosu na željene vrednosti, dok oznake $c_{p}, k_{p}, k_{z}$, $\mathrm{c}_{\mathrm{z}}, \mathrm{c}_{\mathrm{s} \Theta}, \mathrm{c}_{\mathrm{sz}}$ predstavljaju odgovarajuće koeficijente [5].

Kako sile $u$ cilindrima $F_{p}$ i $F_{z}$ zavise od poskakivanja i galopiranja oslonjene mase, moraju se razdvojiti komponente koje izazivaju poskakivanje od onih koje izazivaju galopiranje (blok Rasprezanje definisan na slici 2). U tom smislu treba posmatrati drugu i treću jednačinu iz sistema (1), na osnovu kojih se može zaključiti da postoje relacije koje definišu upravljanje silama poskakivanja i galopiranja oslonjene mase u obliku:

$$
\begin{aligned}
& f_{z r}=-\left(f_{p}+f_{z}\right) \cos \theta \\
& f_{\theta r}=\left(b f_{z}-a f_{\theta}\right) \cos \theta
\end{aligned}
$$

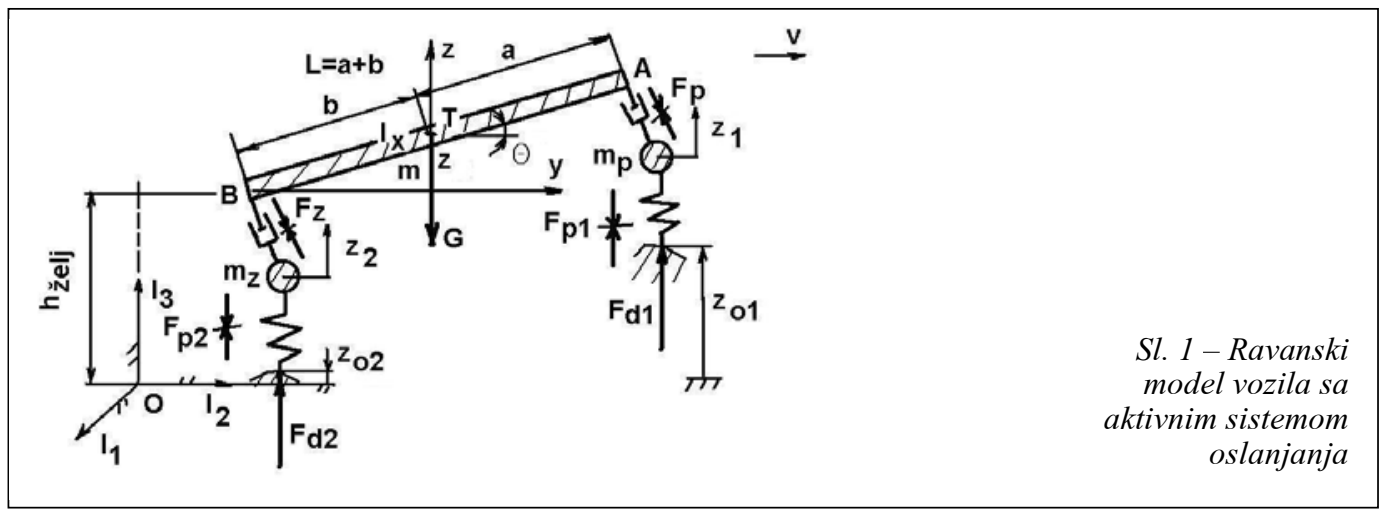




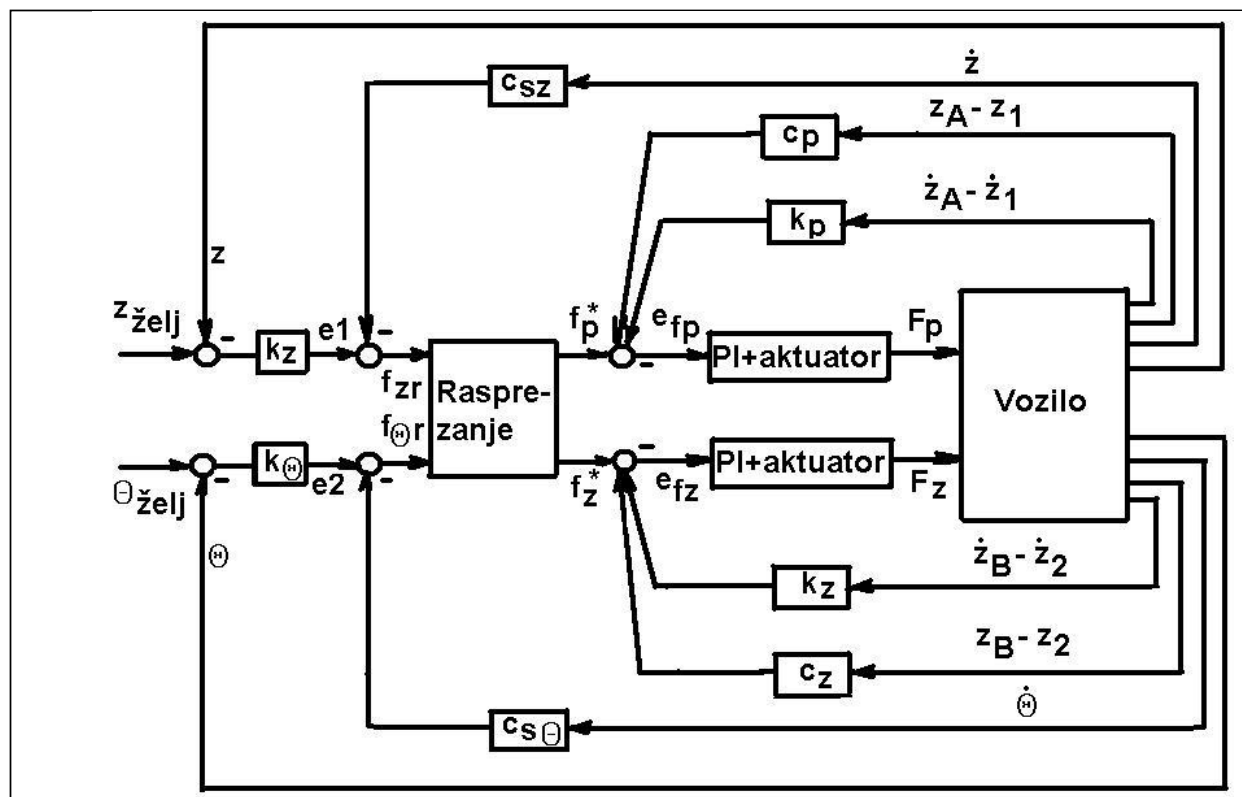

Sl. 2 - Blok-dijagram aktivnog sistema oslanjanja

odakle se dobijaju signali regulacije u obliku:

$$
\begin{aligned}
f_{p}^{*} & =-\frac{b f_{z r}+f_{\theta r}}{L \cos \theta} \\
f_{z}^{*} & =\frac{f_{\theta r}-a f_{z r}}{L \cos \theta}
\end{aligned}
$$

Sa slike 2 očigledne su i sledeće relacije:

$$
\begin{aligned}
& e_{1}=\left(z_{\check{z} e l j}-z\right) k_{z} \\
& e_{2}=\left(\theta_{z \check{z} e l j}-\theta\right) k_{\theta} \\
& f_{z r}=e_{1}-c_{s z} \dot{z} \\
& f_{\theta r}=e_{2}-c_{s \theta} \dot{\theta}
\end{aligned}
$$

Prema dostupnim podacima, kod izvedenih vozila najčešće se koriste proporcionalno integralni (PI) i proporcio- nalno-diferencijalno-integralni kontroleri (PID) [5, 6, 16-32, 34-39, 41-43]. Kod nekih rešenja koriste se i filteri koji imaju zadatak da smanje veličinu dinamičkih pojačanja u oblasti rezonanci oslonjene i neoslonjenih masa $[5,25,26]$. $U$ ovom radu razmatrano je korišćenje integrisanog PI kontrolera i aktuatora, bez upotrebe filtera u povratnoj sprezi, ali uz optimizaciju njegovih karakteristika.

Kao što je poznato $[5,25,26]$, a imajući u vidu sliku 2, karakteristiku integrisanog PI kontrolera i aktuatora opisuju jednačine:

$$
\begin{aligned}
& F_{p}=x[1] e_{f p}+x[2] \int e_{f p} d t \\
& F_{z}=x[3] e_{f z}+x[4] \int e_{f z} d t
\end{aligned}
$$

gde su parametri integrisanog PI kontrolera i aktuatora označeni sa $\mathrm{x}$ [1], x[2], x[3] i x[4], koji su u ovom radu op- 
timizirani, a dinamičke procese sistema opisuju spregnute jednačine (1-5). Imajući u vidu njihov karakter, kao i slučajan ili udarni karakter pobude mikroprofila puta, evidentno je da se moraju rešavati numerički, metodom Runge-Kuta.

Numerička integracija izvršena je sa vremenskim korakom od 0,003 s u 4096 tačaka, što je dovelo do pouzdanosti rezultata u oblasti 0,08 do $166 \mathrm{~Hz}$ [1-3], a to je zadovoljavajuće sa aspekta oscilatorne udobnosti i ponašanja vozila na putu [40].

\section{Metoda optimizacije}

Metoda stohastičke parametarske optimizacije, koja nalazi primenu u optimizaciji oscilatornih parametara motornih vozila, zasniva se na metodama nelinearnog programiranja [4]. Jedna od često primenjivanih metoda nelinearnog programiranja Hooke-Jeeves method, poznata je po ubrzanom procesu pretraživanja funkcije cilja i detaljno je opisana u [4].

Kako u procesu optimizacije postoje ograničenja konstruktivnih parametara, problem se rešava uvođenjem spoljašnjih, ili unutrašnjih kaznenih funkcija. U konkretnom slučaju, za optimizaciju parametara integrisanog PI kontrolera i aktuatora korišćena je metoda stohastičke parametarske optimizacije [7, 8, 11-15] zasnovana na metodi Hooke-Jeeves i spoljašnjim kaznenim funkcijama, čiji je blok-dijagram prikazan na slici 3 [15].

Ocenjeno je celishodnim da se optimalan izbor parametara integrisanog PI kontrolera i aktuatora izvrši sa aspekta oscilatorne udobnosti i ponašanja vozila na putu. U konkretnom slučaju, u skladu sa posmatranim modelom vozila, istovremeno su minimizirana ubrzanja poskaki- vanja i galopiranja oslonjene mase (zahtevi oscilatorne udobnosti) i standardna odstupanja dinamičkih reakcija tla (zahtevi dobrog ponašanja vozila na putu) [37]. Funkcija cilja tada ima sledeći oblik:

$$
\begin{aligned}
& z=\operatorname{rang} 1 * \ddot{z}_{e f}+\operatorname{rang} 2 * \ddot{\theta}_{e f}+ \\
& +\operatorname{rang} 3 * \sigma_{F d 1}+\operatorname{rang} 4 * \sigma_{F d 2}
\end{aligned}
$$

gde je:

rang1-4 - težinski faktori koji definišu rang uticaja veličine uz koju se nalaze, na funkciju cilja $\mathrm{z}$ i omogućavaju prevođenje veličina koje definišu potciljeve $u$ iste jedinice. U nedostatku preporuka za izbor ovih koeficijenata, a u želji da se veći uticaj dâ oscilatornoj udobnosti u odnosu na ponašanje vozila na putu [7, 8, 11-15], usvojene su vrednosti: $\quad$ rang1 $=$ rang2 $=1000 \quad \mathrm{i}$ rang3 = rang4 = 1;

$\ddot{z}_{\text {ef }}, \ddot{\theta}$ - efektivne vrednosti ubrzanja poskakivanja i galopiranja oslonjene mase,

$\sigma_{F d 1}, \sigma_{F d 2}$ - standardna odstupanja dinamičkih reakcija tla.

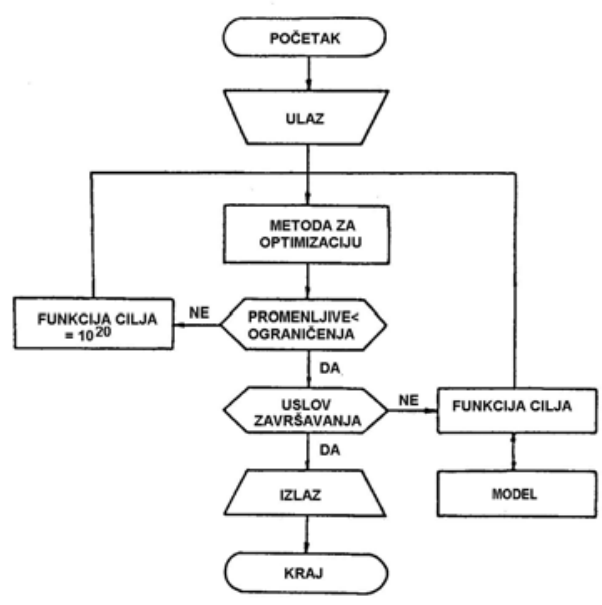

Sl. 3 - Blok-dijagram metode optimizacije 
Pošto u praksi postoje konstruktivna ograničenja, optimizacija je izvršena uz uvođenje oblasti definisanosti posmatranih parametara:

$0<=x[i]<=200, i=1$ do 4

Ocenjeno je celishodnim da se optimizacija izvrši za dve karakteristične vrste pobuda [40]:

- stohastičku, koja je definisana u [7, 8, 11-15], za karakterističnu eksploatacionu brzinu vozila od $30 \mathrm{~m} / \mathrm{s}$ i asfaltni put $\mathrm{u}$ dobrom stanju,

- udarnu (pravougaonu), visine 2 i 5 $\mathrm{cm}$, sa trajanjem od $1,5 \mathrm{~s}$ i početkom $0,5 \mathrm{~s}$ od početka simulacije.

Usvojena je pretpostavka da se zadnji točkovi kreću po istom tragu kao i prednji, tako da je funkcija pobude mikroneravnina na zadnjim točkovima fazno pomerena za veličinu $\mathrm{L} / \mathrm{v}[15,21,30,31,40]$.

Pošto se u praksi problem nalaženja globalnog minimuma rešava tako što optimizacioni proces započinje sa više polaznih vrednosti optimizirajućih parametara [7, 8, 11-15], ocenjeno je celishodnim da u ovom slučaju ovaj proces započne sa tri početne vrednosti tih parametara.

Optimizacija je vršena na računaru Pentium 4 (Iintel 1,8 GHz, $512 \mathrm{Mb}$ RAM), a iterativni proces automatski je prekinut kada su dve susedne vrednosti funkcije cilja bile 1e-15. Vreme optimizacije po jednoj kombinaciji iznosilo je oko 23 minuta, a parametri posmatranog vozila prikazani su u tabeli 1 . Rezultati optimizacije prikazani su u tabeli 2.

\section{Analiza rezultata}

Analizom rezultata iz tabele 2 može se uočiti da je najniža vrednost funkcije cilja, za obe vrste pobude, dobijena u slučaju kada su početne vrednosti optimizirajućih parametara bile najmanje (početne vrednosti 40).

Kao globalni minimum, iz praktičnih razloga, usvaja se funkcija cilja čiji su parametri integrisanog PI kontrolera $\mathrm{i}$ aktuatora: $\quad \mathrm{x} 1_{\mathrm{opt}}=20,00 ; \quad \mathrm{x} 2_{\mathrm{opt}}=4,00$ $\mathrm{x} 3_{\text {opt }}=4,00$ i x $4_{\text {opt }}=7,771 \cdot 10^{-16}$.

Tabela 1

Osnovni podaci o modelu posmatranog vozila $i$ aktivnom sistemu za oslanjanje

\begin{tabular}{|l|l|}
\hline Oslonjena masa, $\mathrm{m}$ & $1500 \mathrm{~kg}$ \\
\hline Neoslonjena masa, $\mathrm{m}_{\mathrm{p}}$ & $59 \mathrm{~kg}$ \\
\hline Neoslonjena masa, $\mathrm{m}_{\mathrm{z}}$ & $59 \mathrm{~kg}$ \\
\hline Moment inercije, $\mathrm{I}_{\mathrm{x}}$ & $2160 \mathrm{kgm}{ }^{2}$ \\
\hline Osno rastojanje $\mathrm{L}$ & $3,1 \mathrm{~m}$ \\
\hline Položaj težišta, $\mathrm{a} / \mathrm{b}$ & $1,4 / 1,7 \mathrm{~m}$ \\
\hline *Krutost pneumatika uz linearni član, $\mathrm{c}_{1}$ & $190000 \mathrm{~N} / \mathrm{m}$ \\
\hline *Krutost pneumatika uz kvadratni član, $\mathrm{c}_{2}$ & $19000000 \mathrm{~N} / \mathrm{m}^{2}$ \\
\hline *Krutost pneumatika uz kubni član, $\mathrm{c}_{3}$ & $19000000 \mathrm{~N} / \mathrm{m}^{3}$ \\
\hline Željena visina vozila, $\mathrm{z}_{\text {želj }}$ & $0,5 \mathrm{~m}$ \\
\hline Željeno galopiranje, $\Theta_{\text {želj }}$ & $0 \mathrm{rad}$ \\
\hline Karakteristična brzina vozila, $\mathrm{v}$ & $30 \mathrm{~m} / \mathrm{s}$ \\
\hline
\end{tabular}

*Za pneumatike na prednjim i zadnjim točkovima.

Rezultati optimizacije

Tabela 2

\begin{tabular}{|l|c|c|c|}
\cline { 2 - 4 } \multicolumn{1}{c|}{} & \multicolumn{3}{c|}{ Slučajna i udarna pobuda } \\
\hline Granične vrednosti & \multicolumn{3}{c|}{$0<=\mathrm{X}[\mathrm{i}]<=200, \mathrm{i}=1 \mathrm{do} 4$} \\
\hline Početne vrednosti & 40,00 & 100,00 & 160,00 \\
\hline Poč. vred. fun. cilja & $6,399 \cdot 10^{+03}$ & $1,032 \cdot 10^{+03}$ & $2,160 \cdot 10^{+03}$ \\
\hline $\mathrm{X}[1]$ & 20,00 & 30,00 & 32,00 \\
\hline $\mathrm{X}[2]$ & 4,00 & 10,00 & 16,00 \\
\hline $\mathrm{X}[3]$ & 4,00 & 10,00 & 16,00 \\
\hline $\mathrm{X}[4]$ & $7,771 \cdot 10^{-16}$ & $1,942 \cdot 10^{-16}$ & $3,108 \cdot 10^{-15}$ \\
\hline Opt. vred. fun. cilja & $3,241 \cdot 10^{+02}$ & $4,112 \cdot 10^{+02}$ & $4,545 \cdot 10^{+02}$ \\
\hline Broj iteracija & 419 & 422 & 332 \\
\hline
\end{tabular}


Pošto posmatrani model vozila predstavlja dinamički sistem sa dve pobude, značajno je da se utvrdi uticaj svake od pobuda na poskakivanje i galopiranje oslonjene mase. To se može učiniti primenom metode linearnih sistema konstantnih parametara [1-3] koja je realizovana u programskom paketu DEMPAR$\mathrm{KOH}$ [10]. Primenom ovog paketa izračunate su funkcije parcijalnih koherenci koje su prikazane na slikama 4 i 5.

Analizom podataka sa slika 4 i 5 može se utvrditi da postoji visoka sprega između funkcija pobude na točkovima i ubr-

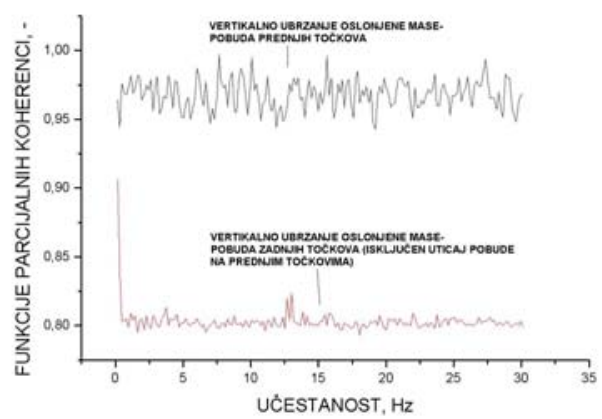

Sl. 4 - Funkcije parcijalnih koherenci: vertikalno ubrzanje poskakivanja oslonjene mase - pobude od mikroprofila puta

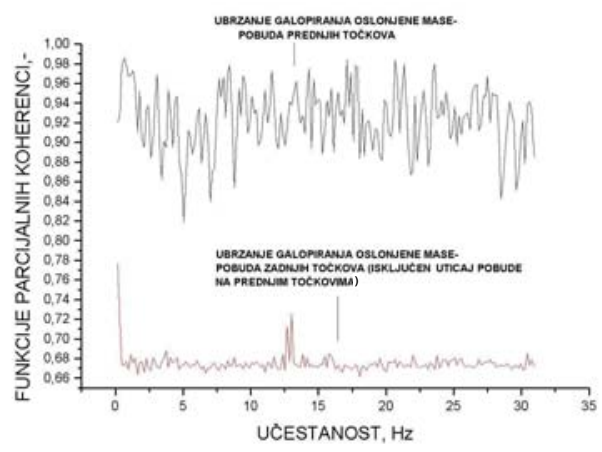

Sl. 5 - Funkcije parcijalnih koherenci: ubrzanje galopiranja oslonjene mase - pobude od mikroprofila puta zanja poskakivanja i galopiranja oslonjene mase vozila. Preciznije rečeno, uticaj pobude prednjih točkova na vertikalno ubrzanje galopiranja veće je od uticaja pobude zadnjih točkova (funkcija koherence oko 0,95 za pobudu na prednjim točkovima, a oko 0,78 za pobudu preko zadnjih točkova). Slična je situacija i sa uticajem pobuda točkova na ubrzanje galopiranja oslonjene mase (funkcija parcijalne koherence oko 0,80 za pobudu na prednjim točkovima $\mathrm{i}$ oko 0,65 na zadnjim točkovima). Pobude mikroneravnina puta više utiču na pojavu poskakivanja oslonjene mase vozila nego na galopiranje, ali je njihov uticaj na obe posmatrane veličine znatan (funkcije parcijalnih koherenci veće od 0,3-0,5 [1-3]).

$\mathrm{Za}$ dalje analize bilo je potrebno da se izračunaju prenosne funkcije poskakivanja i galopiranja oslonjene mase $u$ zavisnosti od pobuda na točkovima. To je realizovano uz korišćenje programskog paketa ANALSIGDEM [9].

Radi ilustracije na slici 6 prikazana je prenosna funkcija galopiranje - pobuda od mikroneravnina puta na zadnjim točkovima, za optimalne vrednosti parametara integrisanog PI kontrolera i aktuatora.

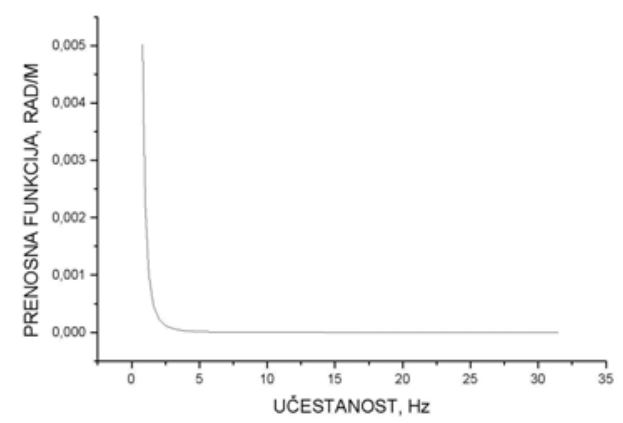

Sl. 6 - Prenosna funkcija: galopiranje oslonjene mase - pobude na zadnjim točkovima, za optimalne parametre integrisanog PI kontrolera $i$ aktuatora 
Analiza svih prenosnih funkcija pokazala je da je dinamičko pojačanje, u posmatranom domenu interesantnih učestanosti $(30 \mathrm{~Hz})$ [40], manje od jedinice. To ukazuje na prihvatljive funkcionalne karakteristike posmatranog sistema aktivnog oslanjanja vozila u svim uslovima eksploatacije, ali i na činjenicu da u slučaju optimalnog izbora parametara integrisanog PI kontrolera i aktuatora ne treba koristiti filtere $\mathrm{u}$ povratnim spregama sistema. To, kao i problem stabilnosti i robustnosti sistema, može biti predmet razmatranja narednih istraživanja.

\section{Zaključak}

Razvijeni postupak stohastičke parametarske optimizacije može biti uspešno korišćen i u slučaju automatske regulacije sistema za oslanjanje vozila. Posmatrani sistem aktivnog oslanjanja sa integrisanim PI kontrolerom i aktuatorom pokazao je povoljne karakteristike. Pri optimalnim parametrima PI kontrolera nisu neophodni filteri $\mathrm{u}$ povratnim spregama sistema. U narednom periodu problem treba posmatrati u okviru prostornih modela vozila i uz analizu stabilnosti i robustnosti aktivnog sistema oslanjanja vozila.

*Istraživanja su realizovana u okviru projekta koji podržava Ministarstvo za nauku i životnu sredinu Vlade Republike Srbije.

Literatura:

[1] Bendat, J. S.; Piersol, A. G.: Random Data-Analysis and measurement procedures, John Wiley and Sons, 2000.

[2] Bendat, J. S.: Nonlinear Systems - Techniques and Applications, John Wiley and Sons, 1998.

[3] Bendat, J. S.; Piersol, A. G.: Engineering Applications of Correlation and Spectral analysis John Wiley \& Sons, New York, 1980 .
[4] Bunday, P.: Basic optimization methods, Spottiswoode Ballantyne, Colchester and London, 1984.

[5] Campos, J. and other: Active Suspension Control of Ground Vehicle Heave and Pitch Motions, Research supported by ARO Grant 39657- MA and Davis Technologies International, Inc., 2005.

[6] Cho, D.; Hedrick, J. K.: Pneumatic Actuators for Vehicle Active Suspension Applications, Journal of Dynamic Systems, Measurement and Control, 1985, Vol. 107/67, pp. 67-72.

[7] Demić, M.: Identification of Vibration parameters for Motor Vehicles, Vehicle System Dynamics, Vol. 27, 1997 pp. 65-88.

[8] Demić, M.: Optimization of Characteristics of Elasto-Damping Elements from Aspect of Oscillatory Comfort and Vehicle Handling, Int.J.of Vehicle Design, Vol. 17, № 1 , 1996 pp. 76-91.

[9] Demić, M.: ANALSIGDEM: Software for signal analysis, www.ptt.yu/korisnici/i/m/imizm034/, 2003.

[10] Demić, M.: DEMPARCOH: Software for partial coherence function calculation, www.ptt.yu/korisnici/i/m/imizm034/, 2003.

[11] Demić, M.: Optimization of Vehicles Elasto-Damping Elements Characteristics From the Aspect of Ride Comfort, Vehicle System Dynamics, Vol. 23 (1994).

[12] Demić, M.: A contribution to optimization of vehicle seats, Int. J. of Vehicle Design. 5/6, 1991, 10 pp. 618-629.

[13] Demić, M.: A contribution to the optimization of the characteristics of elasto-damping elements of passenger cars, Vehicle System Dynamics, Vol. 19, 1990, pages 3-18.

[14] Demić, M.: Analysis of Influence of Design Parameters on Steered Wheels Shimmy oh Heavy Vehicles, Vehicle System Dynamics, Vol. 26, 1996, pp. 343-379.

[15] Demić, M.: Optimizacija oscilatornih sistema motornih vozila (monografija) - Mašinski fakultet u Kragujevcu, 1997.

[16] Donahue, M.: Implementation of an Active Suspension, Preview Controler for Impruved Ride Comfort, M. Sc., The University of California at Berkeley, 2001.

[17] Doule, J. and other: Feedback Control Theory, Mc Millan Publishing Co, 1990.

[18] Florin, M. and other: Active and semiactive suspension design, CONAT2004018, Brashov, 20-22, October, 2004, CD

[19] Frolov, K. V.; Furman, F. A.: Prikladnaja teorija vibrozaštitnih sistem, Mašinostrojenije, Moskva, 1980.

[20] Genta, A.: Motor Vehicle Dynamics, Politecnika di Torino, 2003.

[21] Gillespie, T. D.: Fundamentals of Vehicle Dynamics, SAE, 1992.

[22] Guglu, R.: Active Control of Seat Vibrations of a Vehicle Model Using Various Suspension Alternatives, Turkish J. Eng. Env. Sci. Vol. 27, 2003, pages 361-373.

[23] Hrovat, D.; Hubbard, M.: Optimum Vehicle Suspensions Minimizing RMS Ratllespace, Sprung mass, and Jerk, ASME, 81-WA/DSC-23, 1982, pages 1-9.

[24] Hrovat, D.: A class of Active LQG Optimal Actuators, Automatica, Vol. 18, 1982, No 1, pages 117-119.

[25] Ikenaga, S. and other: Active Suspension Control of Ground Vehicle based on Full Vehicle Model, Davis Technologies International Inc., 2005.

[26] Ikenaga, S. and other: Active Suspension Control Using Novel Strut and Active Filtered Feedback: Design and Implementation, Proceedengs of the 1999. IEEE, Hawaii, USA, Avgust 22-27, 1999, pages 1502-1508.

[27] Jack, H.: Automating Manufacturing Systems with PLCs, Version 4.5, Copyright juckh@gvsu.edu, 2004.

[28] Margolis, D.: Semi-active Control of Wheel Hop in Ground Vehicles, Journal of Vehicle System Dynamics, Vol. 12, 1983, pages 317-330.

[29] Merrit, H.: Hydraulic Control Systems, John Willey \& Sons, Inc., New York, London, Sydney, 1967.

[30] Miliken, W.; Miliken, D.: Race Car Dynamics, SAE, 1995. 
[31] Mitschke, M.: Dynamik der Kraftfahrzeuge, Springer Verlag, 1972.

[32] Moran, A.; Nagai, M.: Performance Analysis of Vehicle Active Suspensions with $H$ Robust Control, 1-st Conference on Motion and Vibration Control, Yokohama, 1999, pages 756-767.

[33] NEWEUL, Manual, TU Stutgart, 2000.

[34] Ostasevicius, V. and other: Investigation of Active Car Suspension with Pneumatic Muscle, SAE, 2002-012206,2002, CD ROM.

[35] Popović, V.: Projektovanje i simulacija sistema aktivnog oslanjanja, Magistarski rad, Mašinski fakultet u Beogradu, 2001.

[36] Rotenberg, R.: Podveska avtomobilja, Mašinostroenie, Moskva, 1972

[37] Silani, E.: Active and semiactive suspensions control strategies in road vehicles, Ph.D. Politecniko di Milano, Dipartimento di electronica e informacione, 2004.
[38] Slaski, G.; Walerjanczyk, W.: Possibilities of impruving active safety by using semi-active suspension, KONMOT 2004, Krakov, pages 597-604.

[39] Seonghark, J. and other: Active Control Method of Automotive System, ICCAS2002, October 16-19, Jeonbuk, Korea, pages 335-338.

[40] Simić D.: Dinamika motornih vozila, Naučna knjiga, Beograd, 1988.

[41] Thompson, A. G.: Optimal and Suboptimal Linear Active Suspension for Road Vehicles, Vehicle System Dynamics, Vol. 13, 1984, pages 61-72.

[42] Tomović, R. i dr.: Uvod u nelinearne sisteme automatskog upravljanja, Naučna knjiga, Beograd, 1974.

[43] Wang, C. Fu: Design and Synthesis of Active and Pasive Vehicle Suspensions, Ph. D. University of Cambridge, Department of Engineering, 2001. 
Sl. 1 - Ravanski model vozila sa aktivnim sistemom oslanjanja

Sl. 2 - Blok-dijagram aktivnog sistema oslanjanja

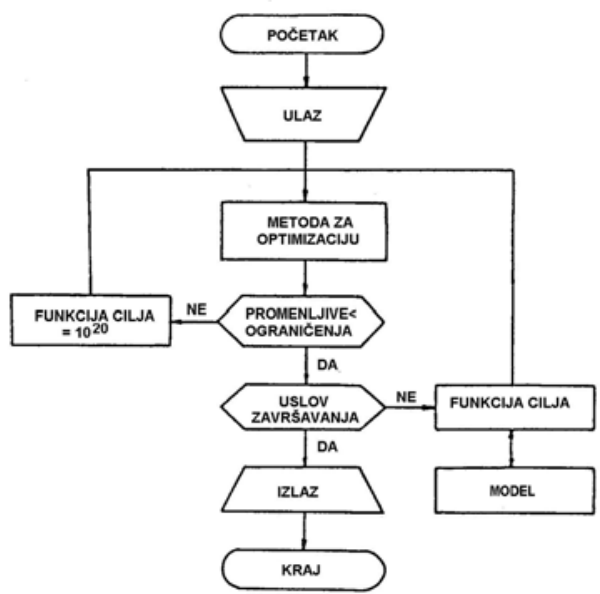

$\overline{\text { VOJNOTEHNIČKI GLAs }}$

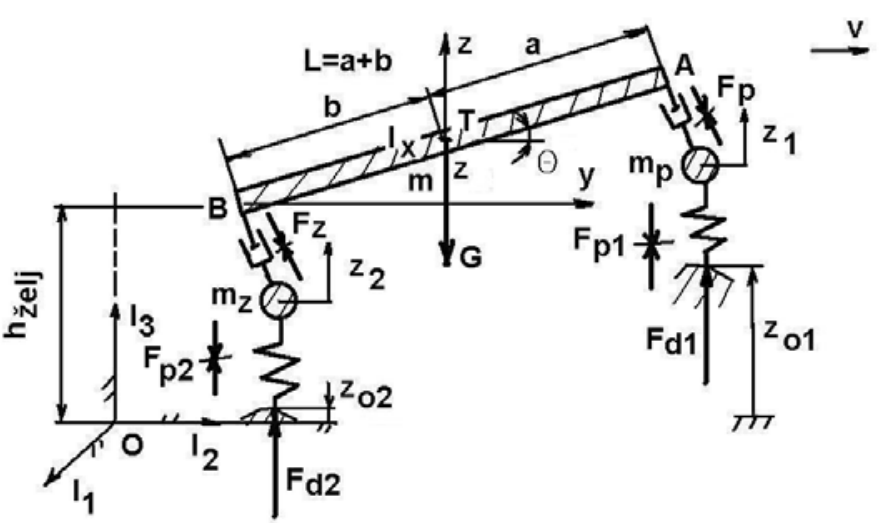



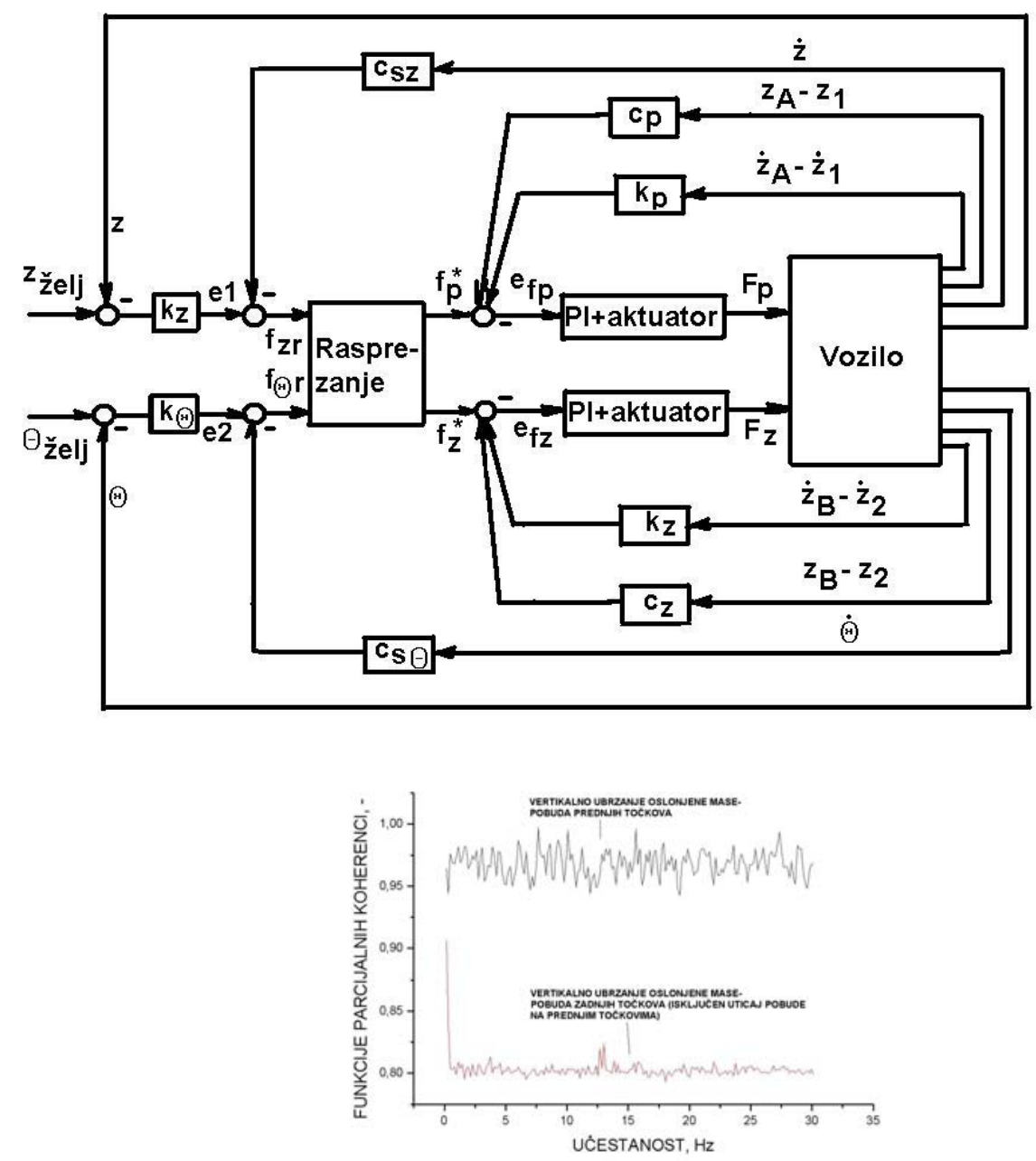

Sl. 3 - Blokdijagram metode optimizacije

Sl. 4 - Funkcije parcijalnih koherenci: vertikalno ubrzanje poskakivanja oslonjene mase - pobude od mikroprofila puta 


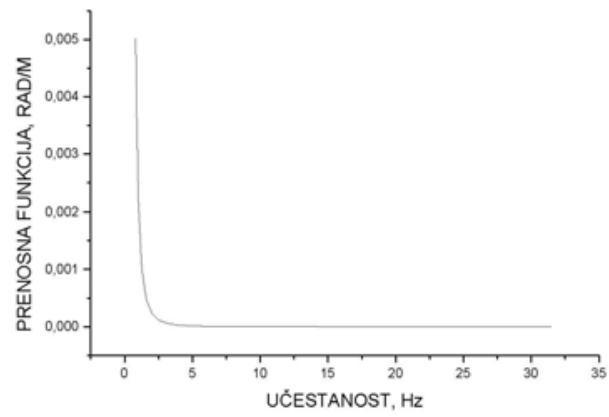

Sl. 5 - Funkcije parcijalnih koherenci: ubrzanje galopiranja oslonjene mase-pobude od mikroprofila puta

Sl. 6-Prenosna funkcija: galopiranje oslonjene mase - pobude na zadnjim točkovima, za optimalne parametre integrisanog PI kontrolera i aktuatora

Rezultati optimizacije

Tabela 2

\begin{tabular}{|l|c|c|c|}
\cline { 2 - 4 } \multicolumn{1}{c|}{} & \multicolumn{3}{c|}{ Slučajna i udarna pobuda } \\
\hline Granične vrednosti & \multicolumn{3}{c|}{$0<=\mathrm{X}[\mathrm{i}]<=200, \mathrm{i}=1$ do 4} \\
\hline Početne vrednosti & 40,00 & 100,00 & 160,00 \\
\hline Poč. vred. fun. cilja & $6,399.10^{+03}$ & $1,032.10^{+03}$ & $2,160.10^{+03}$ \\
\hline $\mathrm{X}[1]$ & 20,00 & 30,00 & 32,00 \\
\hline $\mathrm{X}[2]$ & 4,00 & 10,00 & 16,00 \\
\hline $\mathrm{X}[3]$ & 4,00 & 10,00 & 16,00 \\
\hline $\mathrm{X}[4]$ & $7,771.10^{-16}$ & $1,942.10^{-16}$ & $3,108.10^{-15}$ \\
\hline Opt. vred. fun. cilja & $3,241.10^{+02}$ & $4,112.10^{+02}$ & $4,545.10^{+02}$ \\
\hline Broj iteracija & 419 & 422 & 332 \\
\hline
\end{tabular}

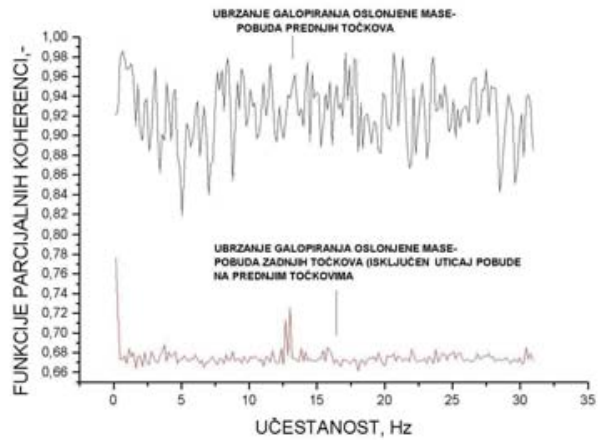


